\title{
Catecholase-Like Activity Studies of Tc-99m Radiopharmaceuticals
}

\author{
E. $\mathrm{CICEK}^{a, *}$ AND B. DeDE ${ }^{b}$ \\ ${ }^{a}$ Faculty of Science and Art, Mehmet Akif Ersoy University, Burdur, Turkey \\ ${ }^{b}$ Faculty of Science and Art, Süleyman Demirel University, Isparta, Turkey
}

\begin{abstract}
Catechol oxidase catalyses the oxidation of a broad range of catechols to the corresponding o-quinones through the four-electron reduction of molecular oxygen to water, without acting on tyrosine. The resulting highly reactive quinones autopolymerize to form brown polyphenolic catechol melanins, a process thought to protect the damaged plant against pathogens or insects. This work describes the catalytic activity of some radiopharmaceuticals like Tc-99m pertechnetate, Tc-99m mercaptoacetyltriglycine (MAG3), Tc-99m nanocolloid, Tc-99m methylenebis(phosphonic acid) (MDP) and Tc-99m methoxyisobutylisonitrile (MIBI) for oxidation of catechol. The catalytic oxidation of 3,5-di-tert-butylcatechol by selected radiopharmaceuticals saturated with molecular oxygen was studied in a homogeneous system. All the radiopharmaceuticals exhibited catecholase-like activity.
\end{abstract}

DOI: 10.12693 /APhysPolA.129.213

PACS: 87.57.uk

\section{Introduction}

Radioisotopes are widely used in medicine, and approximately $90 \%$ of the procedures are devoted to disease diagnosis. Technetium- $99 \mathrm{~m}$ is still the most important radionuclide in clinical medicine due to suitable halflife of $6 \mathrm{~h}$, which minimizes absorbed dose to a patient. Technetium-99m emits $141 \mathrm{keV}$ gamma rays [1,2] and it is convenient for labeling to different pharmaceuticals, resulting in a wide variety of radiopharmaceuticals [3]. Tc-99m is used primarily for monitoring of biological processes in heart, kidney, liver, and brain [1, 2].

Four well-known types of synthesized complexes are nucleases, proteases, tyrosinases and catecholases. Natural enzymes are only active under biotic conditions but synthesized complexes are active also in abiotic conditions and catalyze reactions in extreme conditions (high pressure, heat, acidic and alkaline pH, etc.) [4]. Synthesized enzymes can be used for industrial purposes and medical diagnosis of human brain diseases [5]. Catecholase was isolated for the first time in 1973 [6]. The first crystal structure of purified catecholase from Ipomoea batatas (sweet potato) was described in 1998 [7].

Catecholase is one of the most well-known representative proteins of one of the seven classified protein groups which are known as type-3 active site proteins $[6,8]$. Catecholase oxidizes the catechols as defense mechanisms against insects and pathogenic agents in injured tissues in plants $[8,9]$, following:

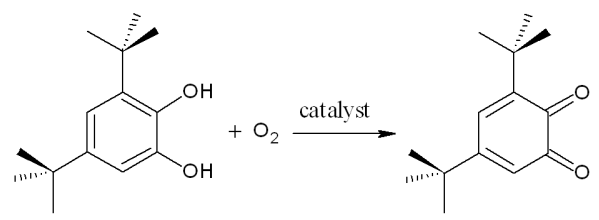

*corresponding author; e-mail: ekrcicek@gmail.com
In literature, the name polyphenol oxidase is used to summarize tyrosinases, catechol oxidases and laccases. It is responsible for the unwanted black-spot formation and important for pigmentation of human skin. On the other hand, radiopharmaceuticals provide an array of specific tools for diagnosing a large number of diseases affecting the bones and major organs of the body such as the heart, brain, liver, kidney and thyroid. Medicinal radiocompounds are applied to a lot of patients every day. Therefore we want to examine the catecholase activity of the selected radiopharmaceuticals. For this purpose 3,5di-tert-butylcatechol (3,5-DTBC) was used as substrate and we report results of our studies on the aerobic oxidation of 3,5-DTBC catalysed by a group of radiopharmaceuticals.

\section{Experimental}

\subsection{Materials and measurement}

Technetium-99m was milked from a $99 \mathrm{Mo} / 99 \mathrm{mTc}$ generator (Monrol AS, Istanbul, Turkey) by $\mathrm{NaCl}$ solution. MIBI (Cardio-Spect, Medi-Radiopharma Ltd, Budapest, Hungary) commercial kit was used for radiolabeling. The UV-vis measurements were performed on a PG T80+ UV-vis spectrophotometer.

\subsection{Catecholase-like activity}

The catalytic oxidation of the 3,5-di-tert-butylcatechol $(3,5$-DTBC) by the Tc- $99 \mathrm{~m}$ pertechnetate, Tc- $99 \mathrm{~m}$ MAG3, Tc-99m nanocolloid, Tc-99m MDP and Tc-99m MIBI was monitored spectrophotometrically recording the increase in absorbance at $400 \mathrm{~nm}$, corresponding to the formation of the o-quinon product 3,5-di-tert-butyl-obenzoquinone (3,5-DTBQ). The most commonly used radiopharmaceuticals were selected for this study. The observed rate constant, $k_{\text {obs }}$ values of the complexes for the o-quinone formation, were also obtained from Eq. (2):

$$
\log \left(A_{\infty} / A_{\infty}-A_{t}\right)=k t,
$$


where $A_{\infty}$ and $A_{t}$ are the absorbance of the formed oquinone at time $t=\infty$ and $t=t$, respectively. The UVvis measurements were performed at room temperature.

\section{Results and discussion}

Among the different catechols used in catechol oxidase model studies, 3,5-DTBC is the most widely used substrate due to its low redox potential for the quinone/catechol couple, which makes it easy to be oxidised to the corresponding quinone 3,5-DTBQ, and its bulky substituents, which make further oxidation reactions such as ring opening slower. The product, 3,5di-tert-butyl-o-quinone (3,5-DTBQ), is considerably stable and has a strong absorption at $\lambda_{\max }=400 \mathrm{~nm}$ $\left(\varepsilon=1900 \mathrm{M}^{-1} \mathrm{~cm}^{-1} ; \mathrm{MeOH}\right)[10,11]$.

Catalytic activity properties of the radiopharmaceuticals are followed monitoring the strong absorbance peak of the 3,5-di-tert-butyl-o-benzoquinone using spectrophotometer (Fig. 1).

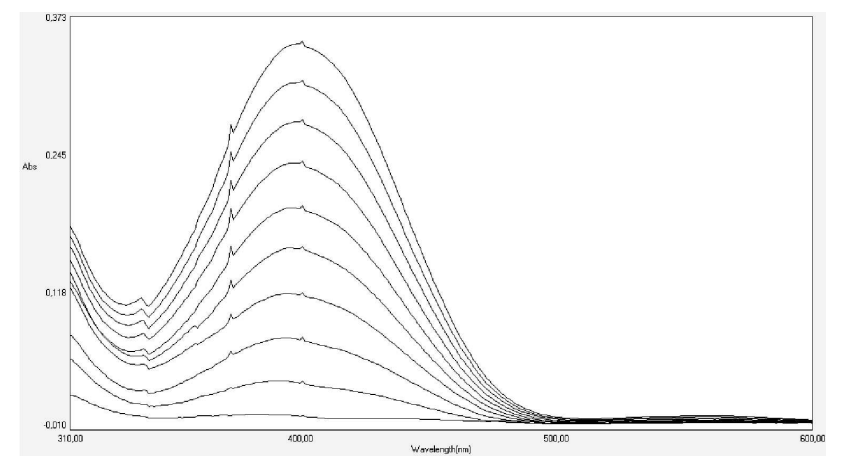

Fig. 1. UV-vis spectral changes for the aerobic oxidation of 3,5-DTBC catalyzed by (5) at room temperature. The spectra have been recorded at every 3 min interval.

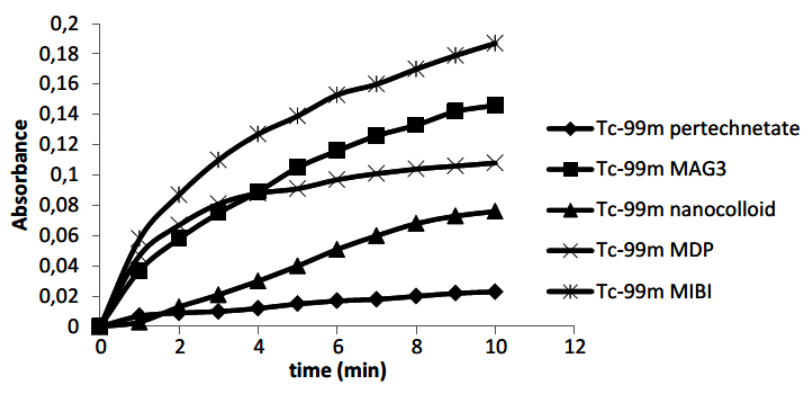

Fig. 2. Plots of absorbance vs. time for aerobic oxidation of 3,5-DTBC in the presence of radiopharmaceuticals (Tc-99m pertechnetate, Tc-99m MAG3, Tc-99m nanocolloid, Tc-99m MDP and Tc-99m MIBI).

Tc-99m pertechnetate (1), Tc-99m mercaptoacetyltriglycine (MAG3) (2), Tc-99m nanocolloid (3), Tc-99m methylenebis(phosphonic acid) (MDP) (4) or Tc-99m methoxyisobutylisonitrile (MIBI) (5) and methanol solution of 3,5-di-tert-butylcatechol were added together in the spectrophotometric cell at ambient temperature. Formation of 3,5-di-tert-butyl-o-benzoquinone was monitored by the increasing in absorbance at $400 \mathrm{~nm}$ with 3 min interval. It was found that all studied radiopharmaceuticals catalyzed the oxidation reaction and exhibited catecholase-like activity (Fig. 2).

A plot of $\log \left(A_{\infty} / A_{\infty}-A_{t}\right)$ versus time of the catecholase activity of the radiopharmaceuticals was achieved and the rate constants for the catalytic oxidation were calculated and given in Table I. The rate constant values of the studied radiopharmaceuticals are different from each other. The order of catalytic activity for the oxidation of 3,5-di-tert-butylcatechol by radiopharmaceuticals is Tc-99m MIBI > Tc-99m MAG3 > Tc$99 \mathrm{~m}$ MDP $>$ Tc-99m nanocolloid $>$ Tc-99m pertechnetate and the initial rate constant value increases from 0.1199 to $0.1602 \mathrm{~min}^{-1}$. Our results show that the Tc$99 \mathrm{~m}$ methoxyisobutylisonitrile (MIBI) showed higher catalytic activity in oxidation of catechol to the corresponding o-quinone compared to the other radiopharmaceuticals.

TABLE I

Rate constant values of the radiopharmaceuticals.

\begin{tabular}{c|c}
\hline \hline Radiopharmaceuticals & Rate constant $\left[\mathrm{min}^{-1}\right]$ \\
\hline Tc-99m pertechnetate & 0.1199 \\
Tc-99m MAG3 & 0.1595 \\
Tc-99m nanocolloid & 0.1383 \\
Tc-99m MDP & 0.1427 \\
Tc-99m MIBI & 0.1602
\end{tabular}

Catalytic activities of metals and their complexes are usually explained in terms of either their redox potentials or molecular structures [12-14]. Redox potential of a metal ion has been considered as one of the critical factors in determining the catalytic activity of the catalyst containing the metal ion towards redox reactions, because the reaction appears to involve a change in the oxidation state of the metal ion during the redox steps. Oxidation state of the technetium is $(1+)$ in Tc$99 \mathrm{~m}$ methoxyisobutylisonitrile (MIBI) (5). The catalytic activity observed for the $(5)$ is probably due to favorable redox potentials of the technetium.

\section{Conclusions}

The most commonly used radiopharmaceuticals were studied for their catecholase enzyme activity. It was found that all used radiopharmaceuticals are observed to be acceptable catalysts towards the oxidation 3,5DTBC to the 3,5-DTBQ. Tc-99m methoxyisobutylisonitrile (MIBI) shows high catecholase activity for the oxidation of catechol to the corresponding o-quinone with the rate constant of $0.1602 \mathrm{~min}^{-1} \mathrm{Tc}-99 \mathrm{~m} \mathrm{MIBI}$ is a coordination complex consisting of the radioisotope technetium$99 \mathrm{~m}$ bound to six methoxyisobutylisonitrile (MIBI) ligands and a member of the isonitrile class of coordination compounds. Coordination nature of the Tc- $99 \mathrm{~m}$ MIBI is differing from the other studied radiopharmaceuticals where the complexing centre of $\mathrm{Tc}$ by $\mathrm{C}_{6}$ moiety. 
We believe that $(1+)$ oxidation state of technetium and octahedral geometry with six MIBI ligands are responsible for the moderate catecholase activity of the Tc-99m MIBI. To our knowledge this is the first report where radiopharmaceuticals exhibit this behaviour.

\section{References}

[1] W.C. Eckelman, A.G. Jones, A. Duatti, R.C. Reba, Drug Discov. Today 18, 984 (2013).

[2] K. Abiraj, R. Mansi, M.L. Tamma, F. Forrer, R. Cescato, J.C. Reubi, K.G. Akyel, H.R. Maecke, Chem. Eur. J. 15, 2115 (2010).

[3] Radiology Fundamentals: Introduction to Imaging and Technology, Eds. H. Singh, J.A. Neutze, Springer, New York 2012

[4] R. Silavi, A. Divsalar, A.A. Saboury, J. Biomol. Struct. Dyn. 30, 752 (2012).

[5] A. Kupan, J. Kaizer, G. Speier, M. Giorgi, M. Reglier, F. Pollreisz, J. Inorg. Biochem. 103, 389 (2009).

[6] K.S. Banu, T. Chattopadhyay, A. Banerjee, S. Bhattacharya, E. Suresh, M. Nethaji, E. Zangrando, D. Das, Inorg. Chem. 47, 7083 (2008).
[7] T. Klabunde, C. Eicken, J.C. Sacchettini, B. Krebs, Nat. Struct. Biol. 5, 1084 (1998).

[8] I.A. Koval, D. Pursche, A.F. Stassen, P. Gamez, B. Krebs, J. Reedijk, Eur. J. Inorg. Chem. 9, 1669 (2003).

[9] W.A. Alves, S.A. Almeida-Filho, M.V. Almeida, A. Paduan-Filho, C.C. Becerra, A.M.C. Ferreira, J. Mol. Catal. A Chem. 198, 63 (2003).

[10] J. Reim, B. Krebs, J. Chem. Soc. Dalton Trans. 1997, 3793 (1997).

[11] R. Wegner, M. Gottschaldt, H. Görls, E.-G. Jager, D. Klemm, Chem. Eur. J. 7, 2143 (2001).

[12] R. Joshi, S.N. Limye, Oxid. Commun. 21, 337 (1998).

[13] I. Mochida, K. Takeshita, J. Phys. Chem. 78, 1653 (1974).

[14] E. Cicek, B. Dede, Acta Phys. Pol. A 125, 875 (2014). 